Review

\title{
Narrative Review of the Post-Operative Management of Prostate Cancer Patients: Is It Really the End of Adjuvant Radiotherapy?
}

\author{
Vincent Bourbonne *(D), Olivier Pradier and Ulrike Schick
}

Citation: Bourbonne, V.; Pradier, O.; Schick, U. Narrative Review of the Post-Operative Management of Prostate Cancer Patients: Is It Really the End of Adjuvant Radiotherapy? Cancers 2022, 14, 719. https:// doi.org/10.3390/cancers14030719

Academic Editors: Hans Christiansen and Robert Michael Hermann

Received: 10 January 2022

Accepted: 28 January 2022

Published: 30 January 2022

Publisher's Note: MDPI stays neutral with regard to jurisdictional claims in published maps and institutional affiliations.

Copyright: (C) 2022 by the authors. Licensee MDPI, Basel, Switzerland. This article is an open access article distributed under the terms and conditions of the Creative Commons Attribution (CC BY) license (https:// creativecommons.org/licenses/by/ $4.0 /)$.
Radiation Oncology Department, University Hospital, 29200 Brest, France; olivier.pradier@chu-brest.fr (O.P.); ulrike.schick@chu-brest.fr (U.S.)

* Correspondence: vincent.bourbonne@chu-brest.fr; Tel.: +33-298223398; Fax: +33-298223087

Simple Summary: Among patients with prostate cancer who have been operated on, a subset harboring high-risk features will present with a biochemical recurrence (BCR). Adjuvant radiotherapy (aRT) was proven to significantly reduce the risk of BCR when compared to salvage radiotherapy (SRT) but suffered from several limitations: a lack of patient selection criteria, a higher treatmentrelated morbidity and an uncertain benefit for long-term clinical endpoints. In the same clinical setting, early SRT (eSRT) appears as non-inferior to aRT with a lower morbidity, replacing aRT as the preferred option. In this review, we insist on the need for multidisciplinary discussions to fully comprehend the individual characteristics of each patient and propose the best treatment strategy for every patient.

Abstract: Despite three randomized trials indicating a significant reduction in biochemical recurrence (BCR) in high-risk patients, adjuvant radiotherapy (aRT) was rarely performed, even in patients harboring high-risk features. aRT is associated with a higher risk of urinary incontinence and is often criticized for the lack of patient selection criteria. With a BCR rate reaching $30-70 \%$ in high-risk patients, a consensus between urologists and radiation oncologists was needed, leading to three different randomized trials challenging aRT with early salvage radiotherapy (eSRT). In these three different randomized trials with event-free survival as the primary outcome and a planned metaanalysis, eSRT appeared as non-inferior to aRT, answering, for some, this never-ending question. For many, however, the debate persists; these results raised several questions among urologists and radiation oncologists. BCR is thought to be a surrogate for clinically meaningful endpoints such as overall survival and cancer-specific survival but may be poorly efficient in comparison with metastasis-free survival. Imaging of rising prostate-specific antigen (PSA), post-operative persistent PSA and BCR was revolutionized by the broader use of MRI and nuclear imaging such as PET-PSMA; these imaging modalities were not analyzed in the previous randomized trials. A sub-group of very high-risk patients could possibly benefit from an adjuvant radiotherapy; but their usual risk factors such as high Gleason score or invaded surgical margins mean they are unable to be selected. More precise biomarkers of early BCR or even metastatic-relapse were developed in this setting and could be useful for the patients' stratification. In this review, we insist on the need for multidisciplinary discussions to fully comprehend the individual characteristics of each patient and propose the best treatment strategy for every patient.

Keywords: adjuvant radiotherapy; early salvage radiotherapy; personalized medicine; biomarker

\section{Introduction}

Approximately $30 \%$ of operated on prostate cancer (PCa) patients will experience biochemical recurrence (BCR), this rising to $50-70 \%$ in very high-risk patients [1-3]. Since 2009-2012 and the publications of three randomized controlled trials [1,4,5] (RCTs) evaluating the benefit of adjuvant radiotherapy (aRT) in PCa patients with high-risk features, 
a gap has opened up between urologists/radiation oncologists who believed these three trials to be practice-changing and those who awaited confirmation of these results on more robust endpoints. Despite a significant benefit for biochemical-free recurrence (bRFS), the only trial in favor of a significant benefit on metastasis-free survival (MFS) and overall survival (OS) was criticized for its design [4]. These debates resulted in a low use of aRT, clinicians fearing the higher genitourinary morbidity associated with aRT when compared to salvage radiotherapy (SRT). The benefit on OS was difficult to evaluate in a population with an expected survival higher than the proposed follow-up.

Given the possible lack of benefit on OS and its higher toxicity profile, aRT was challenged by early SRT (eSRT) in three recently published RCTs [6-8] pooled in a preplanned meta-analysis [9] that proved eSRT to be non-inferior to aRT when considering event-free survival (EFS harmoniously defined as the time from randomization until the first evidence of either biochemical progression (prostate-specific antigen (PSA) $\geq 0.4 \mathrm{ng} / \mathrm{mL}$ and rising after completion of any post-operative radiotherapy), clinical or radiological progression, initiation of a non-trial treatment, death from prostate cancer or a PSA level of at least $2.0 \mathrm{ng} / \mathrm{mL}$ at any time after randomization) with a toxicity profile in favor of eSRT over aRT. For some, these trials closed the discussion between aRT and (e)SRT.

Several reserves must be raised before closing the debate so rapidly. The number of events was quite low in the three trials with a relatively short follow-up. Despite a non-significant benefit in the ARTISTIC meta-analysis, the EFS favored aRT over eSRT in the GETUG-AFU17 and the RAVES trials. Inclusion criteria and study design substantially differed from one trial to another, especially regarding the inclusion/exclusion of patients with a lymph node invasion (LNI). Contemporary imaging modalities such as PET-PSMA were not used, and the performances of recent prognostic tools such as genomic tests [10] were not used or evaluated.

In this review, we aim to revisit the place of aRT and eSRT in patients operated on with high-risk PCa and give an overview of the tools available for personalizing the best treatment selection for each patient.

\section{Adjuvant Radiotherapy Versus Salvage Radiotherapy}

The prostate-specific antigen (PSA) level at the time of post-operative RT was proved to be critical, with a high correlation between the PSA value and the risk of bRFS [11]. Pre-SRT PSA is often used in prediction models among other features such as the PSA doubling time, the use of concomitant or neoadjuvant androgen-deprivation therapy (ADT), the pathology Gleason grade, the surgical margins as well as the presence of LNI [11]. Performance of aRT versus SRT, but only in patients who presented a high-risk of BCR, was thus evaluated. Three RCTs were conducted with different inclusion/exclusion criteria. With a cohort of 425 men with a T3N0M0 PCa treated either with a 60 to 64 Gy aRT or observation, the SWOG S8794 trial showed that aRT reduces the risk of metastasis and benefits OS [4]. It is to be noted that a non-negative post-operative PSA was not considered as an exclusion criteria and $33.4 \%$ of the overall population had a post-operative PSA $>0.2 \mathrm{ng} / \mathrm{mL}$. A similar rate of non-negative post-operative PSA was observed in the EORTC 22911 RCT (rate of 29.9\% in the overall cohort) [1]. Only the ARO 96-02/AUO AP 09/95 study considered this situation as a progression and, thus, as an exclusion criterion [5]. Considering the inconsistency of the post-operative PSA level, some would argue that these trials are more a comparison between (early) SRT vs. delayed SRT than aRT vs. observation. Furthermore, the three RCTs had substantial differences regarding other inclusion criteria: only pT3N0 patients were included in the SWOG S8794 [4], while ARO 96-02/AUO AP 09/95 [5] included pT4 patients and patients in EORTC 22911 [1] had at least two risk features.

Among the three RCTs, only the SWOG S8794 trial used metastasis recurrence-free survival as the primary endpoint, while the EORTC 22911 used bRFS and ARO 96-02/AUO AP 09/95 a progression-free survival (PFS), but defined as the non-occurrence of BCR, local or distant clinical recurrence or death from any cause. The three RCTs met their respective primary endpoints, but both EORTC 22911 and ARO 96-02/ AUO AP 09/95 
failed to prove the benefit of aRT on MFS and OS (secondary endpoints). Results from these three RCTs were pooled in a meta-analysis conducted by the Cochrane Library [12]. Despite the presented biases of these trials, this meta-analysis concluded to an improvement of OS and MFS with aRT over observation but only with a longer follow-up. To be reminded, the mean follow-up durations in the SWOG S8794, EORTC 22911 and ARO 96-02/ AUO AP 09/95 trials were approximately 12.5, 10.6 and 9.4 years, respectively. A meta-analysis published several years before concluded to the absence of an OS benefit of aRT, supporting the absolute need of a longer follow-up [13].

Since these three RCTs, a fourth RCT has also been presented confirming the bRFS benefit of aRT vs. observation but with a mean follow-up of 8.6 years in the observation group, with no benefit on MFS and OS [14].

In spite of this level A data, aRT remained widely underused. For instance, in the United States of America, between 2004 and 2015, only 11.7\% of the 189,240 eligible patients (adverse events on pathology reports) received aRT [15]. The rate rose to $28.9 \%$ in the very high-risk cohort (at least two risk features among $\geq \mathrm{pT} 3 \mathrm{~b}$, pathological Gleason 8-10 and $\mathrm{pN} 1$ ). This under-utilization reflects the puzzlement of urologists and radiation oncologists regarding a clinical setting in which only $30-70 \%$ of the patients will present with an actual BCR and eventually benefit from aRT. The other 30-70\% would experience a higher grade 2 genitourinary morbidity with no actual clinical benefit [1,4,5]. For completeness, the results of these three RCTs are available as Table 1.

Table 1. Key results from the adjuvant vs. salvage radiotherapy trials.

\begin{tabular}{|c|c|c|c|}
\hline Trial & SWOG S8794 [4] & EORTC 22911 [1] & ARO 96-02/AUO AP 09/95 [5] \\
\hline $\begin{array}{l}\text { Inclusion/Exclusion } \\
\text { criteria }\end{array}$ & $\begin{array}{l}\text { Inclusion criteria: } \\
\text { - } \quad \text { pT3 } \\
\text { - } \quad \text { pN0 or pNx } \\
\text { Exclusion criteria: no exclusion criteria } \\
\text { based on the post-operative PSA level }\end{array}$ & $\begin{array}{l}\text { Inclusion criteria: } \mathrm{pT} 2-\mathrm{pT} 3+\mathrm{pN} 0+ \\
\text { at least one adverse feature } \\
\text { - } \quad \text { capsular perforation } \\
\text { - } \quad \text { positive surgical margins } \\
\text { Exclusion criteria: no exclusion } \\
\text { criteria based on the post-operative } \\
\text { PSA level }\end{array}$ & $\begin{array}{l}\text { Inclusion criteria: } \\
\text { - } \quad \text { pT3 or pT4 } \\
\text { - } \quad \text { pN0 } \\
\text { Exclusion criteria: patients with a } \\
\text { detectable post-operative PSA level } \\
\text { were excluded }\end{array}$ \\
\hline $\begin{array}{l}\text { Modality of } \\
\text { radiotherapy }\end{array}$ & $\begin{array}{l}\text { - Prostate fossa: } 60-64 \mathrm{~Gy} / 30-32 \\
\text { fractions } \\
\text { - } \quad \text { Pelvis: no } \\
\text { - } \\
\text { ADT: no }\end{array}$ & 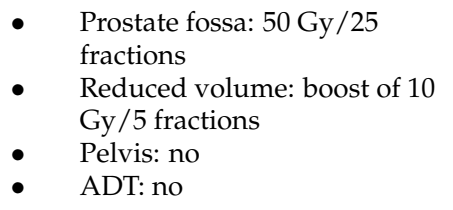 & $\begin{array}{l}\text { - } \quad \text { Prostate fossa: } 60 \mathrm{~Gy} / 30 \\
\text { fractions } \\
\text { - } \quad \text { Pelvis: no } \\
\text { - } \\
\text { ADT: no }\end{array}$ \\
\hline RT trigger & $\begin{array}{l}\text { aRT: Randomization in the } 16 \text { weeks } \\
\text { following surgery, start of } \\
\text { RT in the } 10 \text { working days following } \\
\text { randomization } \\
\text { Observation: rising PSA }\end{array}$ & $\begin{array}{l}\text { aRT: start of RT in the } 16 \text { weeks } \\
\text { following surgery } \\
\text { Observation: rising PSA }\end{array}$ & $\begin{array}{l}\text { aRT: start of RT in the } 6-12 \text { weeks } \\
\text { following surgery } \\
\text { Observation: rising PSA }\end{array}$ \\
\hline Primary Endpoint & MFS & bRFS & $\begin{array}{l}\text { PFS: biochemical recurrence, local or } \\
\text { distant clinical recurrence or death of } \\
\text { any cause }\end{array}$ \\
\hline Secondary Endpoints & $\begin{array}{ll}- & \mathrm{bRFS} \\
- & \mathrm{OS} \\
- & \mathrm{PROs}\end{array}$ & $\begin{array}{ll}- & \mathrm{cPFS} \\
- & \mathrm{OS} \\
- & \mathrm{PROs}\end{array}$ & $\begin{array}{ll}- & \text { bRFS } \\
- & \text { OS } \\
- & \text { PROs }\end{array}$ \\
\hline & Total: $n=425$ & Total: $n=1005$ & Total: $n=385$ \\
\hline Population & $\begin{array}{l}\text { Observation: } \\
n=211\end{array} \quad$ aRT: $n=214 \quad p$ & $\begin{array}{l}\text { Observation:aRT: } \\
n=503 \quad n=502\end{array}$ & $\begin{array}{ll}\text { Observation: } & \text { aRT: } \\
n=159 & n=148\end{array}$ \\
\hline
\end{tabular}


Table 1. Cont.

\begin{tabular}{|c|c|c|c|c|c|c|c|c|c|}
\hline Trial & \multicolumn{3}{|c|}{ SWOG S8794 [4] } & \multicolumn{3}{|c|}{ EORTC 22911 [1] } & \multicolumn{3}{|c|}{ ARO 96-02/AUO AP 09/95 [5] } \\
\hline \multicolumn{10}{|c|}{ Pathology extent of disease } \\
\hline $\begin{array}{l}\text { Positive surgical } \\
\text { margins only }\end{array}$ & - & - & - & $15.7 \%$ & $16.7 \%$ & 0.73 & - & - & - \\
\hline $\begin{array}{l}\text { Excapsular extension } \\
\text { (ECE) }\end{array}$ & $68 \% *$ & $67 \%$ * & 0.91 & $58.8 \%$ & $57.4 \%$ & 0.70 & $47 \%$ & $51 \%$ & 0.56 \\
\hline $\begin{array}{l}\text { Seminal vesicle } \\
\text { invasion (SVI) }\end{array}$ & $11 \%$ & $10 \%$ & 0.86 & $25.4 \%$ & $25.5 \%$ & 0.97 & $17 \%$ & $16 \%$ & 0.93 \\
\hline $\begin{array}{l}\text { Both ECE/positive } \\
\text { margins and SVI }\end{array}$ & $21 \%$ & $23 \%$ & 0.70 & - & - & - & $27 \%$ & $27 \%$ & 1.00 \\
\hline $\begin{array}{l}\text { Invasion of } \\
\text { surrounding organs }\end{array}$ & $0.0 \%$ & $0.0 \%$ & - & - & - & - & $8 \%$ & $3 \%$ & 0.10 \\
\hline \multicolumn{10}{|c|}{ Pathology Gleason score } \\
\hline $2-6$ & $46 \%$ & $57 \%$ & 0.03 & \multirow{3}{*}{\multicolumn{3}{|c|}{ WHO-Evaluated }} & $36 \%$ & $38 \%$ & 0.81 \\
\hline 7 & $38 \%$ & $34 \%$ & 0.45 & & & & $54 \%$ & $50 \%$ & 0.56 \\
\hline $8-10$ & $16 \%$ & $9.0 \%$ & 0.04 & & & & $10 \%$ & $12 \%$ & 0.71 \\
\hline $\begin{array}{c}\text { Central pathology } \\
\text { review }\end{array}$ & \multicolumn{3}{|c|}{ Incomplete: available for $73 \%$} & No & & & \multicolumn{3}{|c|}{ Incomplete: available for $85 \%$} \\
\hline \multicolumn{10}{|l|}{ Pre-RT PSA level } \\
\hline Available data & $186(88.2 \%)$ & $190(88.8 \%)$ & 0.97 & $\begin{array}{l}502 \\
(99.8 \%)\end{array}$ & \multicolumn{2}{|l|}{$497(99.0 \%)$} & - & - & - \\
\hline$<0.2 \mathrm{ng} / \mathrm{mL}$ & $68 \%$ & $65 \%$ & \multirow{2}{*}{0.58} & $68.6 \%$ & \multicolumn{2}{|l|}{$70.3 \%$} & $100 \%$ & $100 \%$ & - \\
\hline$\geq 0.2 \mathrm{ng} / \mathrm{mL}$ & $32 \%$ & $35 \%$ & & $31.2 \%$ & \multicolumn{2}{|l|}{$28.7 \%$} & - & - & - \\
\hline $\begin{array}{l}\text { Percentage of } \\
\text { performed RT }\end{array}$ & $33.2 \%$ & $100 \% ?$ & $<0.0001$ & $30.8 \%$ & \multicolumn{2}{|l|}{$91.0 \%$} & $?$ & $\begin{array}{l}(34 \\
\text { patients } \\
\text { refused } \\
\text { aRT) }\end{array}$ & - \\
\hline $\begin{array}{c}\text { Follow-up (median, } \\
\text { years) }\end{array}$ & $\begin{array}{l}12.5(\mathrm{IQR} \\
11.1-14.0)\end{array}$ & $\begin{array}{l}12.7(\mathrm{IQR} \\
11.4-15.1)\end{array}$ & - & \multicolumn{3}{|c|}{10.6 (IQR 8.4-12.5) } & $\begin{array}{l}9.4(\mathrm{IQR} \\
7.2-10.8)\end{array}$ & $\begin{array}{l}9.3(\mathrm{IQR} \\
7.3-10.7)\end{array}$ & - \\
\hline bRFS (median, years) & 3.1 & 10.3 & - & 6.1 & 13.2 & - & - & - & - \\
\hline PFS (median, years) & - & - & - & - & - & - & 4.9 & $\begin{array}{l}\text { Not } \\
\text { reached }\end{array}$ & - \\
\hline $\begin{array}{l}\text { Proportion with } \\
\text { 10-year MFS }\end{array}$ & $61 \%$ & $71 \%$ & 0.04 & $71.3 \%$ & $76.5 \%$ & 0.07 & - & - & - \\
\hline $\begin{array}{l}\text { Proportion with } \\
\text { 10-year OS }\end{array}$ & $66 \%$ & $74 \%$ & 0.09 & $80.7 \%$ & $76.9 \%$ & 0.16 & - & - & - \\
\hline $\begin{array}{l}\text { Grade } 2 \text { or higher late } \\
\text { genitourinary toxicity }\end{array}$ & $9.5 \%$ & $17.8 \%$ & 0.02 & $13.5 \%$ & $21.3 \%$ & 0.003 & $0.0 \%$ & $2.0 \% * *$ & $0.23^{* *}$ \\
\hline $\begin{array}{c}\text { Grade } 2 \text { or higher late } \\
\text { genitointestinal } \\
\text { toxicity }\end{array}$ & $0.0 \%$ & $3.3 \%$ & 0.02 & $1.9 \%$ & $2.5 \%$ & 0.47 & $0.0 \%$ & $1.4 \%$ & 0.42 \\
\hline
\end{tabular}

* Patients with positives margins only (no ECE) could be included. ${ }^{* *}$ Incontinence was not assessed. Abbreviations wd: working days, RT: radiotherapy, aRT: adjuvant radiotherapy, SRT: salvage radiotherapy, ADT: androgen deprivation therapy, IQR: Inter-Quartile Range, bRFS: biochemical recurrence-free survival defined as the time from randomization to biochemical recurrence, MFS: metastasis recurrence-free survival, PFS: progression-free survival, cPFS: clinical progression-free survival, PROs: patient reported outcomes.

Genitourinary morbidity after post-operative radiotherapy is correlated to the delay between surgery and start of RT and the patient's complete functional recovery [16]. Two conflicting issues, thus, seem to oppose themselves: the EFS and the quality of life of our patients.

\section{Adjuvant Radiotherapy Versus Early Salvage Radiotherapy}

Early salvage radiotherapy (eSRT) is defined as the delivery of SRT to patients with low level rising PSA values (PSA $>0.1-0.2 \mathrm{ng} / \mathrm{mL}$ ). Use of eSRT is supported by solid 
retrospective data such as multi-institutional retrospective studies [17]. With 510 included patients, no significant differences in terms of distant metastasis and mortality when compared to aRT were observed. This absence of significant difference in mortality and the lower rate of genitourinary morbidity when compared to aRT led to eSRT being often preferred by some urologists, even in patients harboring pathological risk factors. Three separate RCTs were thus conducted to evaluate the benefit of aRT over eSRT. Again, these RCTs differ on their respective primary endpoints and inclusion/exclusion criteria but were pooled in a planned meta-analysis [9]. None of the RADICALS-RT, RAVES or GETUG-17 demonstrated a significant benefit on MFS or OS (secondary endpoints), the respective endpoints being bRFS for the RAVES trial and EFS for the RADICALS-RT and GETUG17 trials. Interestingly, the median follow-up was significantly shorter than the "aRT vs. observation" trials with respective FUs of $4.9,6.1$ and 6.3 years. The only positive RCT on aRT vs. observation for MFS was that with the longest follow-up (14.7 years for the aRT cohort and 12.9 for the observation cohort). Such a short follow-up is especially troublesome in this setting because of several points:

- When given (RADICALS-RT and GETUG-AFU-17), ADT artificially prolongs bRFS. Indeed, BCR under ADT at this stage of the disease almost never happens. On the aRT arm, ADT is administered shortly after the randomization and probably 1 to 2 months before the start of aRT. On the eSRT arm, ADT and eSRT could start concomitantly. This design adds a systematic bias that probably negatively impacts the aRT's results

- Because of the definition of BCR, patients with the same biochemical control can be classified differently only because of their affected treatment group. For instance, in the GETUG-AFU-17 trial: BCR will be reached as soon as the PSA rises to $0.4 \mathrm{ng} / \mathrm{mL}$ at least 6 months after RT completion for the aRT arm, whereas in the SRT arm, BCR will be reached at the time of the follow-up meetings several months after RT completion. Similarly, defining the bRFS from the date of randomization contributes to this statistical bias. This difference adds a systematic extension of the bRFS in the SRT arm that is problematic with such a short follow-up. This directly induces a possible bias as observed in the RAVES trial with a 5-year BCR-free rate of $86 \%$ and $87 \%$ for the aRT and eSRT arm, while the 8-year BCR-free rate fell to $80 \%$ and $75 \%$ for the aRT and eSRT arms, respectively [7].

- $\quad$ The GETUG-AFU-17 trial was closed prematurely because of the low rate of events.

The results from the three RCTs (summarized in Table 2) were pooled in the ARTISTIC meta-analysis that seemed to confirm the "observation" attitude [9], with the authors concluding to the absence of benefit of aRT over eSRT for all patients. None of the patients seemed to significantly benefit from aRT, even on the sub-group analysis. It is to be noted that patients with a Gleason score $\geq 8$, a high CAPRA-S risk group and especially patients with an LNI were insufficiently represented (respective rates of $15.1 \%, 35.2 \%$ and 3.9\%). Data on very high-risk patients (CAPRA-S risk score $\geq 8$ ) are unavailable. Knowing the 2.4-fold increase in risk with a 2-point increase on the CAPRA-S, these detailed data are needed [18]. These very high-risk patients are those who probably benefit the most from a post-operative treatment [19]. Unfortunately, in spite of their efforts, data regarding very high-risk patients are inconclusive and need further research. Among the risk features, LNI needs a specific focus given its low representation in the previously presented trials. 
Table 2. Key results from the adjuvant vs. early salvage radiotherapy trials.

\begin{tabular}{|c|c|c|c|c|c|c|c|c|c|}
\hline Trial & \multicolumn{3}{|c|}{ RADICALS-RT [8] } & \multicolumn{3}{|c|}{ GETUG-AFU 17 [6] } & \multicolumn{3}{|c|}{ RAVES [7] } \\
\hline $\begin{array}{l}\text { Inclusion/Exclusion } \\
\text { criteria }\end{array}$ & \multicolumn{3}{|c|}{$\begin{array}{ll}\text { - } & \text { pT3 or pT4 } \\
\text { Gleason score } \geq 7 \\
\text { - } & \text { Positive surgical margins } \\
\text { Exclusion criteria: } \\
\text { - } \quad \begin{array}{l}\text { patients with a detectable } \\
\text { post-operative PSA level were } \\
\text { excluded } \\
\text { pN0/pNx was not an exclusion } \\
\text { criteria }\end{array} \\
\end{array}$} & \multicolumn{3}{|c|}{$\begin{array}{l}\text { Inclusion criteria: } \\
\text { - } \quad \text { pT3-pT4a } \\
\text { - pN0 or pNx } \\
\text { Exclusion criteria: patients with a } \\
\text { detectable post-operative PSA level were } \\
\text { excluded }\end{array}$} & \multicolumn{3}{|c|}{$\begin{array}{l}\text { Inclusion criteria: patients with at least } \\
\text { one risk feature among: } \\
\text { - } \quad \text { pT3a or pT3b } \\
\text { - } \quad \text { positive surgical margins } \\
\text { Exclusion criteria: } \\
\text { - } \quad \text { patients with a detectable } \\
\text { post-operative PSA level were } \\
\text { excluded } \\
\text { pN0/pNx was not an exclusion } \\
\text { criteria }\end{array}$} \\
\hline Modality of radiotherapy & \multicolumn{3}{|c|}{$\begin{array}{l}\text { Prostate fossa: } 66 \text { Gy/33 fractions } \\
\text { or } 52.5 \text { Gy } / 20 \text { fractions } \\
\text { Pelvis: at the physician's discretion } \\
\text { - } \\
\text { ADT: if participating in } \\
\text { RADICALS-HD, random allocation } \\
\text { to } 0,6 \text { or } 24 \text { months of ADT }\end{array}$} & \multicolumn{3}{|c|}{$\begin{array}{l}\text { - } \quad \text { Prostate fossa: } 66 \mathrm{~Gy} / 33 \text { fractions } \\
\text { - } \quad \text { ADTis: at the physician's discretion } \\
\text { ADonths for all patients }\end{array}$} & \multicolumn{3}{|c|}{$\begin{array}{l}\text { - } \quad \text { Prostate fossa: } 64 \mathrm{~Gy} / 32 \text { fractions } \\
\text { - } \quad \text { Pelvis: no } \\
\text { ADT: no }\end{array}$} \\
\hline RT trigger & \multicolumn{3}{|c|}{$\begin{array}{l}\text { aRT: initiation within both } 2 \text { months of } \\
\text { randomization and } 26 \text { weeks of radical } \\
\text { prostatectomy } \\
\text { Observation: initiation within } 2 \text { months of } \\
\text { biochemical recurrence } \\
\text { Start of RT could be delayed by up to } \\
2 \text { months in case of ADT }\end{array}$} & \multicolumn{3}{|c|}{$\begin{array}{l}\text { aRT: start of RT within 3-6 months of } \\
\text { radical prostatectomy } \\
\text { Observation: when BCR occurred }\end{array}$} & \multicolumn{3}{|c|}{$\begin{array}{l}\text { aRT: start of RT within } 4 \text { months of radical } \\
\text { prostatectomy } \\
\text { Observation: within } 4 \text { months of BCR }\end{array}$} \\
\hline Primary Endpoint & \multicolumn{3}{|c|}{ EFS } & \multicolumn{3}{|c|}{ EFS } & \multicolumn{3}{|c|}{ bRFS } \\
\hline Secondary Endpoints & $\begin{array}{ll}: & \text { MFS } \\
: & \text { OS } \\
: & \text { Disease- } \\
& \text { PROs } \\
\end{array}$ & ecific surv & & $\begin{array}{ll}- & \text { MFS } \\
: & \text { OS } \\
- & \text { Acute a } \\
& \text { Change }\end{array}$ & $\begin{array}{l}\text { late toxici } \\
\text { QOL }\end{array}$ & & $\begin{array}{ll}\text { - } & \text { Time to in } \\
\text { - } & \text { Time to loc } \\
\text { - } & \text { OSogressio } \\
\text { - } & \text { Acute and }\end{array}$ & $\begin{array}{l}\text { tiation of } \\
\text { al, region } \\
\text { late toxic }\end{array}$ & distant \\
\hline \multirow[b]{2}{*}{ Population } & \multicolumn{3}{|l|}{ Total: $n=1396$} & \multicolumn{3}{|l|}{ Total: $n=424$} & \multicolumn{3}{|l|}{ Total: $n=333$} \\
\hline & $\begin{array}{l}\text { Observation: } \\
n=699\end{array}$ & $\begin{array}{l}\text { aRT: } \\
n=697\end{array}$ & $p$ & $\begin{array}{l}\text { Observation: } \\
n=212\end{array}$ & $\begin{array}{l}\text { aRT: } \\
n=212\end{array}$ & $p$ & $\begin{array}{l}\text { Observation: } \\
n=167\end{array}$ & $\begin{array}{l}\text { aRT: } \\
n=166\end{array}$ & $p$ \\
\hline \multicolumn{10}{|c|}{ Pathology extent of disease } \\
\hline Positive surgical margin & $63 \%$ & $63 \%$ & - & - & - & - & $68 \%$ & $66 \%$ & 0.79 \\
\hline $\begin{array}{l}\text { Excapsular extension or } \\
\text { positive margin (pT3a) }\end{array}$ & $56 \%$ & $58 \%$ & 0.48 & $77 \%$ & $77 \%$ & - & - & - & - \\
\hline $\begin{array}{l}\text { Seminal vesicle invasion } \\
\text { (pT3b) }\end{array}$ & $19 \%$ & $18 \%$ & 0.68 & $20 \%$ & $21 \%$ & 0.89 & $20 \%$ & $19 \%$ & 0.93 \\
\hline $\begin{array}{l}\text { Invasion of surrounding } \\
\text { organs (pT4) }\end{array}$ & $1 \%$ & $1 \%$ & - & $2 \%$ & $1 \%$ & 0.65 & - & - & - \\
\hline \multicolumn{10}{|c|}{ Pathology Gleason score } \\
\hline $2-6$ & $7 \%$ & $7 \%$ & - & $10 \%$ & $10 \%$ & - & $2 \%$ & $4 \%$ & 0.45 \\
\hline 7 & $75 \%$ & $77 \%$ & 0.42 & $79 \%$ & $82 \%$ & 0.51 & $83 \%$ & $81 \%$ & 0.74 \\
\hline $8-10$ & $18 \%$ & $16 \%$ & 0.36 & $11 \%$ & $8 \%$ & 0.37 & $15 \%$ & $15 \%$ & - \\
\hline \multicolumn{10}{|c|}{ Lymph node involvement } \\
\hline Involved & $5 \%$ & $4 \%$ & \multirow{2}{*}{0.44} & $0 \%$ & $0 \%$ & - & $1 \%$ & $0 \%$ & 0.61 \\
\hline Not involved or unknown & $95 \%$ & $96 \%$ & & $100 \%$ & $100 \%$ & - & $100 \%$ & $99 \%$ & \\
\hline \multicolumn{10}{|c|}{ CAPRA-S risk group } \\
\hline Low $(0-2)$ & $8 \%$ & $8 \%$ & - & \multirow{3}{*}{\multicolumn{2}{|c|}{ Not available }} & & $13 \%$ & $13 \%$ & - \\
\hline Intermediate (3-5) & $55 \%$ & $55 \%$ & - & & & & $60 \%$ & $59 \%$ & 0.94 \\
\hline $\operatorname{High}(\geq 6)$ & $37 \%$ & $37 \%$ & - & & & & $27 \%$ & $29 \%$ & 0.78 \\
\hline Central pathology review & No & & & No & & & $\begin{array}{l}\text { Available but pa } \\
\text { on pathology res }\end{array}$ & $\begin{array}{l}\text { hology } r \\
\text { ults from }\end{array}$ & $\begin{array}{l}\mathrm{ng} \text { based } \\
\text { institution }\end{array}$ \\
\hline $\begin{array}{l}\text { Percentage of } \\
\text { performed RT }\end{array}$ & $32.0 \%$ & $93 \%$ & $<0.0001$ & $54 \%$ & $97 \%$ & $<0.0001$ & $50 \%$ & $95.8 \%$ & $<0.0001$ \\
\hline Follow-up (median, years) & 4.9 & & & $\begin{array}{l}6.2(\mathrm{IQR} \\
3.9-8.3)\end{array}$ & $\begin{array}{l}6.5 \text { (IQR } \\
4.3-8.1)\end{array}$ & - & 6.1 (IQR 4.3-7.5) & & - \\
\hline $\begin{array}{l}\text { Proportion with } \\
\text { 5-year EFS }\end{array}$ & $85 \%$ & $88 \%$ & 0.12 & $90 \%$ & $92 \%$ & 0.58 & $89 \%$ & $86 \%$ & 0.51 \\
\hline
\end{tabular}


Table 2. Cont.

\begin{tabular}{|c|c|c|c|c|c|c|c|c|c|c|}
\hline \multicolumn{2}{|c|}{ Trial } & \multicolumn{3}{|c|}{ RADICALS-RT [8] } & \multicolumn{3}{|c|}{ GETUG-AFU 17 [6] } & \multicolumn{3}{|c|}{ RAVES [7] } \\
\hline \multicolumn{2}{|c|}{$\begin{array}{l}\text { Proportion with } \\
\text { 8-year EFS }\end{array}$} & - & - & - & - & - & - & $79 \%$ & $80 \%$ & 0.93 \\
\hline \multicolumn{2}{|c|}{ MFS } & \multicolumn{3}{|l|}{ Immature } & \multicolumn{3}{|l|}{ Immature } & - & - & - \\
\hline \multicolumn{2}{|c|}{ Proportion with 8-year OS } & \multicolumn{3}{|l|}{ Immature } & \multicolumn{3}{|l|}{ Immature } & $97 \%$ & $92 \%$ & 0.08 \\
\hline \multicolumn{2}{|c|}{$\begin{array}{l}\text { Grade } 2 \text { or higher late } \\
\text { genitourinary toxicity }\end{array}$} & - & - & - & $7 \%$ & $27 \%$ & $<0.0001$ & $54 \% *$ & $70 \%$ * & 0.002 \\
\hline \multicolumn{2}{|c|}{$\begin{array}{l}\text { Grade } 2 \text { or higher late } \\
\text { genitointestinal toxicity }\end{array}$} & - & - & - & $5 \%$ & $8 \%$ & 0.24 & $10 \%$ * & $14 \%$ * & 0.53 \\
\hline \multirow{3}{*}{$\begin{array}{c}\text { Late } \\
\text { diarrhea }\end{array}$} & G1 or 2 & $8 \%$ & $17 \%$ & $<0.0001$ & $7 \%$ & $12 \%$ & - & \multirow{3}{*}{ 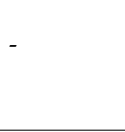 } & & \\
\hline & G3 & $<1 \%$ & $1 \%$ & - & $0 \%$ & $0 \%$ & - & & & \\
\hline & G4 & $0 \%$ & $<1 \%$ & - & $0 \%$ & $0 \%$ & - & & & \\
\hline \multirow{3}{*}{$\begin{array}{c}\text { Late } \\
\text { proctitis }\end{array}$} & G1 or 2 & $5 \%$ & $13 \%$ & $<0.0001$ & $3 \%$ & $8 \%$ & - & \multirow{3}{*}{ - } & & \\
\hline & G3 & $<1 \%$ & $1 \%$ & - & $0 \%$ & $1 \%$ & - & & & \\
\hline & G4 & $0 \%$ & $0 \%$ & - & $0 \%$ & $0 \%$ & - & & & \\
\hline \multirow{3}{*}{$\begin{array}{c}\text { Late } \\
\text { cystitis }\end{array}$} & G1 or 2 & $7 \%$ & $13 \%$ & $<0.0005$ & $0 \%$ & $0 \%$ & - & \multirow{3}{*}{ - } & & \\
\hline & G3 & $1 \%$ & $1 \%$ & - & $0 \%$ & $<1 \%$ & - & & & \\
\hline & G4 & $0 \%$ & $0 \%$ & - & $0 \%$ & $0 \%$ & - & & & \\
\hline \multirow{3}{*}{$\begin{array}{c}\text { Late } \\
\text { hematuria }\end{array}$} & G1 or 2 & $4 \%$ & $12 \%$ & $<0.0001$ & $4 \%$ & $12 \%$ & - & & & \\
\hline & G3 & $<1 \%$ & $4 \%$ & - & $<1 \%$ & $2 \%$ & - & & & \\
\hline & G4 & $0 \%$ & $0 \%$ & - & $<1 \%$ & $0 \%$ & - & & & \\
\hline \multirow{3}{*}{$\begin{array}{c}\text { Late } \\
\text { urethral } \\
\text { stricture }\end{array}$} & G1 or 2 & $3 \%$ & $6 \%$ & 0.0025 & $6 \%$ & $9 \%$ & - & \multirow{3}{*}{ - } & & \\
\hline & G3 & $2 \%$ & $4 \%$ & - & $0 \%$ & $<1 \%$ & - & & & \\
\hline & G4 & $<1 \%$ & $0 \%$ & - & $0 \%$ & $0 \%$ & - & & & \\
\hline & & & $\begin{array}{l}\text { ne } \mathrm{R} \\
\text { The } \\
\text { Abbr } \\
\text { nce, } \\
\text { repo }\end{array}$ & $\begin{array}{l}\text { ial, no d } \\
\text { are thu } \\
\text { s: EFS: E } \\
\text { any cau } \\
\text { comes, }\end{array}$ & $\begin{array}{l}\text { rences w } \\
\text { nerestim } \\
\text { L: BCR: Bi } \\
\text { L: Quality }\end{array}$ & $\begin{array}{l}\text { ade b } \\
\text { when } \\
\text { l (Eve } \\
\text { ical R } \\
\text { fe, IQI }\end{array}$ & $\begin{array}{l}\text { acute at } \\
\text { d to the } \\
\text { defineo } \\
\text { ce, MFS: } \\
\text { Quartile }\end{array}$ & $\begin{array}{l}\text { late toxici } \\
\text { ETUG-AF } \\
\text { the occur } \\
\text { etastasis re } \\
\text { nge. }\end{array}$ & $\begin{array}{l}\text { the } p \\
\text { and th } \\
\text { of } B C \\
\text { nce-fre }\end{array}$ & $\begin{array}{l}\text { ted to> } \\
\text { ICAL } \\
\text { l or di } \\
\text { ival, } \mathrm{P}\end{array}$ \\
\hline
\end{tabular}

\section{Impact of an LNI in the Choice of aRT and eSRT}

LNI is known to be a major risk feature for PCa patients because it represents a shift in the disease from a localized to a metastatic state. Management of these patients is, thus, a priority. To our knowledge, no prospective trial evaluating the benefit of aRT over SRT or (e)SRT has focused specifically on patients with a pN1 status [20].

LNI was an exclusion criteria for the three RCTs comparing aRT and observation $[1,4,5]$. Retrospective data suggest a clinical benefit of aRT over ADT alone in certain subsets of patients. Adjuvant radiotherapy significantly impacts cancer-specific mortality in two sub-groups of patients: patients with 1 to 2 positives nodes with a Gleason score 7-10 or pT3b/PT4/positive margins (group 3) or patients with 3-4 positives nodes (group 4) [21]. Patients with $\geq 4$ positive nodes probably were micro-metastatic. The rest of the patients did not harbor enough risk features to benefit from aRT as previously proven [19]. aRT was systematically associated with ADT. This simple selection tool was externally validated with a significant reduction in overall mortality in the aRT + ADT arm when compared to the ADT alone arm. In Groups 3 and 4, hazard ratios were respectively $0.75(0.62-0.91)$ and $0.57(0.38-0.86)$ [22]. Even without this group selection, the addition of aRT to ADT in pN1 patients still appears to be beneficial to overall survival [23].

As previously stated, only two of the three RCTs pooled in the ARTISTIC meta-analysis allowed patients with LNI to be included. Patients with LNI represent a very small subset of the overall cohort (3.0\%). No conclusions regarding the impact of LNI on the effect of RT timing could thus be proposed, leaving clinicians wondering about the generalizability of the aRT vs. eSRT results to the pN1 patients. 


\section{Impact of ADT on the Choice of aRT and eSRT}

A major possible confounding factor was the possibility (or non-possibility) of concomitant ADT, depending on the RCT. The addition of 24 months of ADT to SRT was significantly associated with longer MFS and OS in the RTOG 9601 trial [24]. The CAPRA-S score was not evaluable in this specific study but, again, a low rate of Gleason $\geq 8$ score is observed $(17.3 \%)$ and a low PSA level at the time of randomization, with $53.3 \%$ of the patients having a PSA level $<0.7 \mathrm{ng} / \mathrm{mL}$. However, this benefit of ADT was not consistent across the whole range of patients. On a multicentric cohort, only patients with more aggressive characteristics at the time of SRT (pT3b/4 and grade group $\geq 4$ or $\mathrm{pT} 3 \mathrm{~b} / 4$ and pre-SRT PSA $\geq 0.4 \mathrm{ng} / \mathrm{mL}$ ) had a significantly better MFS with ADT [25]. The value of the pre-SRT PSA level was confirmed as an efficient surrogate for the benefit of ADT. In patients with a pre-SRT PSA level $<0.6 \mathrm{ng} / \mathrm{mL}$, the benefit of adding ADT on OS was not significant, probably because of the lower OS benefit counterbalanced by the cardiovascular morbidity associated with ADT [26]. Pre-SRT PSA thus stands out as a potential prognostic biomarker for patient selection before ADT + SRT. Delivered in selected patients with a very high-risk profile but a long life expectancy and no post-operative dysfunction, aRT could be seen as an effective possibility to postpone ADT. Furthermore, data supporting the addition of ADT to aRT remain scarce, with several studies reporting the absence of an OS benefit [27], probably due to the low PSA value at the time of aRT.

A note must be made regarding the design of the six RCTs focusing on eSRT, SRT and aRT. Apart from the RADICALS trial, none of the RCTs were designed or powered enough to evaluate the impact of ADT in the post-operative setting.

\section{Optimizing the Selection of Patients for aRT: Novel Biological and Diagnostic Approaches}

All the data seem to converge towards a single challenge, namely the selection of patients for either aRT or (e)SRT. Numerous clinical features are taken into account, with a consensus being adopted on the definition of high-risk and very high-risk patients. Data on high-risk patients are temporary awaiting a longer follow-up, while data on very high-risk patients are scarce or unavailable. The ARTISTIC meta-analysis used the CAPRA-S risk score to combine risk features and stratify the included patients but did not find a significant benefit of aRT over eSRT, even in patients with a high CAPRA-S score. Being an aggregate study-level analysis and not an individual patient-level analysis, all subset analyses in the ARTISTIC meta-analysis were probably underpowered. Before detailing other selection modalities, the importance of a central pathology review must be stressed [28,29]. Pathology review is a major possible cofounding factor in these RCTs in which inclusion criteria are pathology-based. On the three RCTs evaluating aRT vs. eSRT, none had a central pathology review for all patients. Apart from clinical and pathology-based features, other selection modalities were developed. Firstly, one could think disease staging at the time of aRT/SRT could impact the treatment's outcomes. For example, patients, with an unknown LNI status at the time of post-operative RT and who would be treated with SRT delivered to the prostate fossa only, would not benefit from SRT. With its high sensitivity, 68-GA-PSMA positron emission tomography (PET) appears as the most efficient imaging modality to detect an eventual LNI. However, despite its high sensitivity, performing such an exam did not significantly impact patients' outcomes [30], probably because of the low rate of detection in the case of PSA $<0.2 \mathrm{ng} / \mathrm{mL}$ when aRT or eSRT is performed [31]. PSMA PET associated with a magnetic resonance imaging could enhance the detection rate [32] and possibly modify the definition of radiotherapy target volumes [33,34]. Several clinicians are currently rethinking their approach in the case of BCR, incorporating PSMA PET as a tool to guide diagnostic or therapeutic management. Differing treatments until PSMA PET reveals a relapse site amenable to targeted radiotherapy may be tempting, but given the prognostic value of a negative PSMA PET in the post-operative setting [35], differing RT should only be performed within clinical trials. 
Characterization of the disease with genomic or radiomics approaches also appear as an efficient tools for patients' selection. In this setting and on a sub-analysis of 486 patients, a genomic-classifier was significantly correlated with MFS and OS [10]. The Decipher test impacts decision making among patients considered for aRT/eSRT and is an independent predictor of response to RT [36,37]. The Decipher tests stratifies patients among three riskbased cohorts. Patients with a score $>0.6$ have the highest risk of recurrence [38]. Such a tool could guide the selection of patients for ADT, aRT/SRT or observation, with a cut-off of 0.6 [10]. A radiomics model based on a sole radiomic feature was externally validated as an efficient tool for the stratification of patients based on their BCR risk [39]. Combining these genomics and radiomics approaches ("radiogenomics") resulted in higher performances when compared to the Decipher or the CAPRA scores [40]. However, selecting patients at higher risk of bRFS or even metastatic-relapse does not necessarily mean that these patients would benefit more from aRT than from eSRT. Analyzing the performances of these advanced tools in the RAVES, RADICALS-RT and GETUG-AFU-17 trials would be interesting. A summary of the performances of these prognostic tools is available as Table 3 . Before clinical implementation, these promising biological and diagnostic tools should be evaluated in clinical trials; the key point remaining the selection of patients that would possibly benefit from aRT on long-term endpoints.

Table 3. Performances of the novel biomarkers for the prediction of patients' outcomes.

\begin{tabular}{cccc}
\hline Prediction Tool & Endpoint & Result & Setting \\
\hline Presalvage PSA level [27] & OS & HR 1.57, $p=0.004$ & Post-hoc analysis \\
\hline Genomics-only [10] & MFS & HR 1.26, $p<0.001$ & Post-hoc analysis \\
\cline { 2 - 3 } & OS & HR 1.21, $p<0.001$ & \\
\hline Radiomics-only [39] & bRFS & HR 5.5, $p<0.0001$ & External validation \\
\hline Radiomics + Genomics [40] & bRFS & HR 1.6 $p=0.04$ & $\begin{array}{c}\text { Multi-institutional } \\
\text { validation }\end{array}$ \\
\hline
\end{tabular}

Abbreviations: PSA: Prostate-Specific Antigen, HR: Hazard Ratio, IC95\%: 95\% Confidence Interval, OS: Overall Survival, MFS: metastasis recurrence-free survival, bRFS: biochemical recurrence-free survival.

\section{Discussion}

As presented, several key clinical issues were defined to summarize the abundance of literature on the aRT vs. (e)SRT debate. Data regarding aRT vs. SRT and aRT vs. eSRT were limited to published RCTs, while data regarding the impact of LNI and ADT were limited to RCTs or large and/or multicentric retrospective studies. This methodology has the advantage of a clear and concise report but with a risk of selection bias. However, the goal was mainly to discuss current literature data and offer practical insights on present and future perspectives in this clinical setting.

\section{Conclusions}

With a 5-years follow-up, adjuvant radiotherapy does not appear to significantly impact MFS and OS over eSRT in high-risk PCa patients. These aRT vs. eSRT RCTs confirmed the low value of bRFS as an intermediate surrogate of MFS and OS [41] and probably ended the time for the use of aRT at all. Duration of the follow-up is crucial when focusing on post-operative clinical endpoints where, with only observation, median bRFS ranges from 3.1 to 6.1 years and median OS is often immature due to the lack of followup. Clinicians should, thus, be careful not to completely bury aRT as some very selected patients might benefit from it. Delivered in patients with a very high-risk profile such as LNI or a combination of high-risk features (Decipher score $>0.6$ or CAPRA-S score $\geq 8$ or $\geq 2$ risk factors such as invasion seminal vesicle invasion and positive surgical margins) but a long life expectancy and no post-operative dysfunction, aRT could be seen as an effective possibility to postpone ADT without compromising quality and quantity of life. Data regarding these very high-risk patients need further research. Selection of these patients 
is a challenge in a situation where clinical and pathological features are insufficient and where imaging modalities such as PET and MRI could be helpful. Translational research should be incorporated into the multidisciplinary management of these patients.

Author Contributions: Writing—original draft preparation: V.B.; writing-review and editing: V.B., U.S.; supervision: O.P.; validation: V.B., O.P., U.S. All authors have read and agreed to the published version of the manuscript.

Funding: This research received no external funding.

Conflicts of Interest: The authors declare no conflict of interest.

\section{References}

1. Bolla, M.; van Poppel, H.; Tombal, B.; Vekemans, K.; Da Pozzo, L.; de Reijke, T.M.; Verbaeys, A.; Bosset, J.F.; van Velthoven, R.; Colombel, M.; et al. Postoperative radiotherapy after radical prostatectomy for high-risk prostate cancer: Long-term results of a randomised controlled trial (EORTC trial 22911). Lancet 2012, 380, 2018-2027. [CrossRef]

2. Kupelian, P.A.; Elshaikh, M.; Reddy, C.A.; Zippe, C.; Klein, E.A. Comparison of the efficacy of local therapies for localized prostate cancer in the prostate-specific antigen era: A large single-institution experience with radical prostatectomy and external-beam radiotherapy. J. Clin. Oncol. Off. J. Am. Soc. Clin. Oncol. 2002, 20, 3376-3385. [CrossRef]

3. Han, M.; Partin, A.W.; Zahurak, M.; Piantadosi, S.; Epstein, J.I.; Walsh, P.C. Biochemical (prostate specific antigen) recurrence probability following radical prostatectomy for clinically localized prostate cancer. J. Urol. 2003, 169, 517-523. [CrossRef]

4. Thompson, I.M.; Tangen, C.M.; Paradelo, J.; Lucia, M.S.; Miller, G.; Troyer, D.; Messing, E.; Forman, J.; Chin, J.; Swanson, G.; et al. Adjuvant radiotherapy for pathological T3N0M0 prostate cancer significantly reduces risk of metastases and improves survival: Long-term followup of a randomized clinical trial. J. Urol. 2009, 181, 956-962. [CrossRef]

5. Wiegel, T.; Bartkowiak, D.; Bottke, D.; Bronner, C.; Steiner, U.; Siegmann, A.; Golz, R.; Storkel, S.; Willich, N.; Semjonow, A.; et al Adjuvant radiotherapy versus wait-and-see after radical prostatectomy: 10-year follow-up of the ARO 96-02/AUO AP 09/95 trial. Eur. Urol. 2014, 66, 243-250. [CrossRef] [PubMed]

6. Sargos, P.; Chabaud, S.; Latorzeff, I.; Magne, N.; Benyoucef, A.; Supiot, S.; Pasquier, D.; Abdiche, M.S.; Gilliot, O.; GraffCailleaud, P.; et al. Adjuvant radiotherapy versus early salvage radiotherapy plus short-term androgen deprivation therapy in men with localised prostate cancer after radical prostatectomy (GETUG-AFU 17): A randomised, phase 3 trial. Lancet Oncol. 2020, 21, 1341-1352. [CrossRef]

7. Kneebone, A.; Fraser-Browne, C.; Duchesne, G.M.; Fisher, R.; Frydenberg, M.; Herschtal, A.; Williams, S.G.; Brown, C.; Delprado, W.; Haworth, A.; et al. Adjuvant radiotherapy versus early salvage radiotherapy following radical prostatectomy (TROG 08.03/ANZUP RAVES): A randomised, controlled, phase 3, non-inferiority trial. Lancet Oncol. 2020, 21, 1331-1340. [CrossRef]

8. Parker, C.C.; Clarke, N.W.; Cook, A.D.; Kynaston, H.G.; Petersen, P.M.; Catton, C.; Cross, W.; Logue, J.; Parulekar, W.; Payne, H.; et al. Timing of radiotherapy after radical prostatectomy (RADICALS-RT): A randomised, controlled phase 3 trial. Lancet 2020, 396, 1413-1421. [CrossRef]

9. Vale, C.L.; Fisher, D.; Kneebone, A.; Parker, C.; Pearse, M.; Richaud, P.; Sargos, P.; Sydes, M.R.; Brawley, C.; Brihoum, M.; et al. Adjuvant or early salvage radiotherapy for the treatment of localised and locally advanced prostate cancer: A prospectively planned systematic review and meta-analysis of aggregate data. Lancet 2020, 396, 1422-1431. [CrossRef]

10. Feng, F.Y.; Huang, H.C.; Spratt, D.E.; Zhao, S.G.; Sandler, H.M.; Simko, J.P.; Davicioni, E.; Nguyen, P.L.; Pollack, A.; Efstathiou, J.A.; et al. Validation of a 22-Gene Genomic Classifier in Patients With Recurrent Prostate Cancer: An Ancillary Study of the NRG/RTOG 9601 Randomized Clinical Trial. JAMA Oncol. 2021, 7, 544-552. [CrossRef]

11. Stephenson, A.J.; Scardino, P.T.; Kattan, M.W.; Pisansky, T.M.; Slawin, K.M.; Klein, E.A.; Anscher, M.S.; Michalski, J.M.; Sandler, H.M.; Lin, D.W.; et al. Predicting the outcome of salvage radiation therapy for recurrent prostate cancer after radical prostatectomy. J. Clin. Oncol. Off. J. Am. Soc. Clin. Oncol. 2007, 25, 2035-2041. [CrossRef] [PubMed]

12. Daly, T.; Hickey, B.E.; Lehman, M.; Francis, D.P.; See, A.M. Adjuvant radiotherapy following radical prostatectomy for prostate cancer. Cochrane Database Syst. Rev. 2011, 12, CD007234. [CrossRef] [PubMed]

13. Morgan, S.C.; Waldron, T.S.; Eapen, L.; Mayhew, L.A.; Winquist, E.; Lukka, H.; Genitourinary Cancer Disease Site Group of the Cancer Care Ontario Program in Evidence-based, C. Adjuvant radiotherapy following radical prostatectomy for pathologic T3 or margin-positive prostate cancer: A systematic review and meta-analysis. Radiother. Oncol. J. Eur. Soc. Ther. Radiol. Oncol. 2008, 88, 1-9. [CrossRef] [PubMed]

14. Hackman, G.; Taari, K.; Tammela, T.L.; Matikainen, M.; Kouri, M.; Joensuu, T.; Luukkaala, T.; Salonen, A.; Isotalo, T.; Petas, A.; et al. Randomised Trial of Adjuvant Radiotherapy Following Radical Prostatectomy Versus Radical Prostatectomy Alone in Prostate Cancer Patients with Positive Margins or Extracapsular Extension. Eur. Urol. 2019, 76, 586-595. [CrossRef] [PubMed]

15. Rakic, N.; Sood, A.; Dalela, D.; Arora, S.; Malovana, U.; Keeley, J.; Rogers, C.; Peabody, J.; Menon, M.; Abdollah, F. A Nationwide Persistent Underutilization of Adjuvant Radiotherapy in North American Prostate Cancer Patients. Clin. Genitourin. Cancer 2020, 18, 489-499.e6. [CrossRef] 
16. Zaffuto, E.; Gandaglia, G.; Fossati, N.; Dell'Oglio, P.; Moschini, M.; Cucchiara, V.; Suardi, N.; Mirone, V.; Bandini, M.; Shariat, S.F.; et al. Early Postoperative Radiotherapy is Associated with Worse Functional Outcomes in Patients with Prostate Cancer. J. Urol. 2017, 197, 669-675. [CrossRef]

17. Fossati, N.; Karnes, R.J.; Boorjian, S.A.; Moschini, M.; Morlacco, A.; Bossi, A.; Seisen, T.; Cozzarini, C.; Fiorino, C.; Noris Chiorda, B.; et al. Long-term Impact of Adjuvant Versus Early Salvage Radiation Therapy in pT3N0 Prostate Cancer Patients Treated with Radical Prostatectomy: Results from a Multi-institutional Series. Eur. Urol. 2017, 71, 886-893. [CrossRef]

18. Cooperberg, M.R.; Hilton, J.F.; Carroll, P.R. The CAPRA-S score: A straightforward tool for improved prediction of outcomes after radical prostatectomy. Cancer 2011, 117, 5039-5046. [CrossRef]

19. Abdollah, F.; Suardi, N.; Cozzarini, C.; Gallina, A.; Capitanio, U.; Bianchi, M.; Sun, M.; Fossati, N.; Passoni, N.M.; Fiorino, C.; et al. Selecting the optimal candidate for adjuvant radiotherapy after radical prostatectomy for prostate cancer: A long-term survival analysis. Eur. Urol. 2013, 63, 998-1008. [CrossRef]

20. D'Rummo, K.A.; Chen, R.C.; Shen, X. Narrative review of management strategies and outcomes in node-positive prostate cancer. Transl. Androl. Urol. 2021, 10, 3176-3187. [CrossRef]

21. Abdollah, F.; Karnes, R.J.; Suardi, N.; Cozzarini, C.; Gandaglia, G.; Fossati, N.; Vizziello, D.; Sun, M.; Karakiewicz, P.I.; Menon, M.; et al. Impact of adjuvant radiotherapy on survival of patients with node-positive prostate cancer. J. Clin. Oncol. Off. J. Am. Soc. Clin. Oncol. 2014, 32, 3939-3947. [CrossRef] [PubMed]

22. Abdollah, F.; Dalela, D.; Sood, A.; Keeley, J.; Alanee, S.; Briganti, A.; Montorsi, F.; Peabody, J.O.; Menon, M. Impact of Adjuvant Radiotherapy in Node-positive Prostate Cancer Patients: The Importance of Patient Selection. Eur. Urol. 2018, 74, 253-256. [CrossRef] [PubMed]

23. Touijer, K.A.; Karnes, R.J.; Passoni, N.; Sjoberg, D.D.; Assel, M.; Fossati, N.; Gandaglia, G.; Eastham, J.A.; Scardino, P.T.; Vickers, A.; et al. Survival Outcomes of Men with Lymph Node-positive Prostate Cancer After Radical Prostatectomy: A Comparative Analysis of Different Postoperative Management Strategies. Eur. Urol. 2018, 73, 890-896. [CrossRef] [PubMed]

24. Shipley, W.U.; Seiferheld, W.; Lukka, H.R.; Major, P.P.; Heney, N.M.; Grignon, D.J.; Sartor, O.; Patel, M.P.; Bahary, J.P.; Zietman, A.L.; et al. Radiation with or without Antiandrogen Therapy in Recurrent Prostate Cancer. N. Engl. J. Med. 2017, 376, 417-428. [CrossRef] [PubMed]

25. Gandaglia, G.; Fossati, N.; Karnes, R.J.; Boorjian, S.A.; Colicchia, M.; Bossi, A.; Seisen, T.; Cozzarini, C.; Di Muzio, N.; Noris Chiorda, B.; et al. Use of Concomitant Androgen Deprivation Therapy in Patients Treated with Early Salvage Radiotherapy for Biochemical Recurrence After Radical Prostatectomy: Long-term Results from a Large, Multi-institutional Series. Eur. Urol. 2018, 73, 512-518. [CrossRef] [PubMed]

26. Dess, R.T.; Sun, Y.; Jackson, W.C.; Jairath, N.K.; Kishan, A.U.; Wallington, D.G.; Mahal, B.A.; Stish, B.J.; Zumsteg, Z.S.; Den, R.B.; et al. Association of Presalvage Radiotherapy PSA Levels After Prostatectomy With Outcomes of Long-term Antiandrogen Therapy in Men With Prostate Cancer. JAMA Oncol. 2020, 6, 735-743. [CrossRef]

27. Bravi, C.A.; Tin, A.; Vertosick, E.; Mazzone, E.; Bandini, M.; Dell'Oglio, P.; Stabile, A.; Gandaglia, G.; Fossati, N.; Sjoberg, D.; et al. Androgen deprivation therapy in men with node-positive prostate cancer treated with postoperative radiotherapy. Urol. Oncol. 2020, 38, 204-209. [CrossRef]

28. Bottke, D.; Golz, R.; Storkel, S.; Hinke, A.; Siegmann, A.; Hertle, L.; Miller, K.; Hinkelbein, W.; Wiegel, T. Phase 3 study of adjuvant radiotherapy versus wait and see in pT3 prostate cancer: Impact of pathology review on analysis. Eur. Urol. 2013, 64, 193-198. [CrossRef]

29. Montironi, R.; Lopez-Beltran, A.; Cheng, L.; Montorsi, F.; Scarpelli, M. Central prostate pathology review: Should it be mandatory? Eur. Urol. 2013, 64, 199-201, discussion 202-193. [CrossRef]

30. Schmidt-Hegemann, N.S.; Zamboglou, C.; Thamm, R.; Eze, C.; Kirste, S.; Spohn, S.; Li, M.; Stief, C.; Bolenz, C.; Schultze-Seemann, W.; et al. A Multi-Institutional Analysis of Prostate Cancer Patients with or without 68Ga-PSMA PET/CT Prior to Salvage Radiotherapy of the Prostatic Fossa. Front. Oncol. 2021, 11, 723536. [CrossRef]

31. Schmidt-Hegemann, N.S.; Fendler, W.P.; Buchner, A.; Stief, C.; Rogowski, P.; Niyazi, M.; Eze, C.; Li, M.; Bartenstein, P.; Belka, C.; et al. Detection level and pattern of positive lesions using PSMA PET/CT for staging prior to radiation therapy. Radiat. Oncol. 2017, 12, 176. [CrossRef] [PubMed]

32. Kranzbuhler, B.; Muller, J.; Becker, A.S.; Garcia Schuler, H.I.; Muehlematter, U.; Fankhauser, C.D.; Kedzia, S.; Guckenberger, M.; Kaufmann, P.A.; Eberli, D.; et al. Detection Rate and Localization of Prostate Cancer Recurrence Using (68)Ga-PSMA-11 PET/MRI in Patients with Low PSA Values </=0.5 ng/mL. J. Nucl. Med. Off. Publ. Soc. Nucl. Med. 2020, 61, 194-201. [CrossRef]

33. Robin, S.; Jolicoeur, M.; Palumbo, S.; Zilli, T.; Crehange, G.; De Hertogh, O.; Derashodian, T.; Sargos, P.; Salembier, C.; Supiot, S.; et al. Prostate Bed Delineation Guidelines for Postoperative Radiation Therapy: On Behalf Of The Francophone Group of Urological Radiation Therapy. Int. J. Radiat. Oncol. Biol. Phys. 2021, 109, 1243-1253. [CrossRef] [PubMed]

34. Barbosa, F.G.; Queiroz, M.A.; Nunes, R.F.; Viana, P.C.C.; Marin, J.F.G.; Cerri, G.G.; Buchpiguel, C.A. Revisiting Prostate Cancer Recurrence with PSMA PET: Atlas of Typical and Atypical Patterns of Spread. Radiographics 2019, 39, 186-212. [CrossRef]

35. Emmett, L.; van Leeuwen, P.J.; Nandurkar, R.; Scheltema, M.J.; Cusick, T.; Hruby, G.; Kneebone, A.; Eade, T.; Fogarty, G.; Jagavkar, R.; et al. Treatment Outcomes from (68)Ga-PSMA PET/CT-Informed Salvage Radiation Treatment in Men with Rising PSA After Radical Prostatectomy: Prognostic Value of a Negative PSMA PET. J. Nucl. Med. Off. Publ. Soc. Nucl. Med. 2017, 58, 1972-1976. [CrossRef] 
36. Gore, J.L.; du Plessis, M.; Santiago-Jimenez, M.; Yousefi, K.; Thompson, D.J.S.; Karsh, L.; Lane, B.R.; Franks, M.; Chen, D.Y.T.; Bandyk, M.; et al. Decipher test impacts decision making among patients considering adjuvant and salvage treatment after radical prostatectomy: Interim results from the Multicenter Prospective PRO-IMPACT study. Cancer 2017, 123, 2850-2859. [CrossRef] [PubMed]

37. Dalela, D.; Loppenberg, B.; Sood, A.; Sammon, J.; Abdollah, F. Contemporary Role of the Decipher(R) Test in Prostate Cancer Management: Current Practice and Future Perspectives. Rev. Urol. 2016, 18, 1-9. [PubMed]

38. Davicioni, E.; Choeurng, V.; Luo, B.; Yousefi, K.; Shin, H.; Haddad, Z.; Ross, A.; Schaeffer, E.M.; Den, R.B.; Dicker, A.; et al. Recalibration of genomic risk prediction models in prostate cancer to improve individual-level predictions. J. Clin. Oncol. 2015, 33, e16122. [CrossRef]

39. Bourbonne, V.; Fournier, G.; Vallieres, M.; Lucia, F.; Doucet, L.; Tissot, V.; Cuvelier, G.; Hue, S.; Le Penn Du, H.; Perdriel, L.; et al. External Validation of an MRI-Derived Radiomics Model to Predict Biochemical Recurrence after Surgery for High-Risk Prostate Cancer. Cancers 2020, 12, 814. [CrossRef] [PubMed]

40. Li, L.; Shiradkar, R.; Leo, P.; Algohary, A.; Fu, P.; Tirumani, S.H.; Mahran, A.; Buzzy, C.; Obmann, V.C.; Mansoori, B.; et al. A novel imaging based Nomogram for predicting post-surgical biochemical recurrence and adverse pathology of prostate cancer from pre-operative bi-parametric MRI. EBioMedicine 2021, 63, 103163. [CrossRef]

41. Gharzai, L.A.; Jiang, R.; Wallington, D.; Jones, G.; Birer, S.; Jairath, N.; Jaworski, E.M.; McFarlane, M.R.; Mahal, B.A.; Nguyen, P.L.; et al. Intermediate clinical endpoints for surrogacy in localised prostate cancer: An aggregate meta-analysis. Lancet Oncol. 2021, 22, 402-410. [CrossRef] 